\title{
Decomposition and Decoupling Analysis of Industrial Solid Waste in the Yangtze River Economic Belt
}

\author{
Ma Teli ${ }^{1, *}$ \\ ${ }^{1}$ School of Business, Hohai University, 213022 Changzhou, China
}

\begin{abstract}
In this paper, LMDI method is used to analyze the driving factors of industrial solid waste production in the Yangtze River Economic Belt from 2005 to 2018, and the decoupling state is analyzed by Tapio indicator. We found that:1)Industrial pollution intensity effect and industrial structure effect inhibited industrial solid waste production, while regional output effect and population size effect played a role in increasing the pollution; (2)in different periods, the decoupling states of industrial solid waste in the Yangtze River Economic Belt were weak decoupling, weak decoupling and expansive negative decoupling. The decoupling indicator showed a trend of first decreasing and then increasing. It is suggested to guide investment to environment-friendly industries and strengthen the research on solid waste reduction technology.
\end{abstract}

\section{Introduction}

Industry is the most important material production sector, which plays an irreplaceable role in economic development. However, industrial production, especially low-end industrial production, will produce a large number of pollutants, including solid wastes. The industrial solid waste may pollute the atmosphere, soil and water, impairing environmental quality and longterm sustainable development ${ }^{[1]}$. For an extended period of time, the characteristics of industry in China were high energy consumption and high emissions ${ }^{[2]}$. China is confronted with the problem of large quantity of industrial solid waste ${ }^{[3]}$. The Yangtze River Economic Belt, a major national strategic development area, has an important impact on China's economic development and ecological security. The industrial economy in the economic belt is active, with industrial added value accounting for more than $40 \%$ of China. From $2005-$ 2018 , the average annual growth rate of its industrial added value was $10.00 \%$, while the average annual growth of industrial solid waste production was $7.42 \%$. The solid pollution generated in the process of rapid industrial growth posed a serious threat to the environment in the Yangtze River Economic Belt. Identifying the driving factors of industrial solid waste production in the Yangtze River Economic Belt, studying the decoupling relationship between solid pollution and economic development, and putting forward industrial pollution reduction policies can promote the industrial green transformation of the Yangtze River Economic Belt, and provide reference for other regions' high-quality development.

\section{Literature review}

\subsection{Decomposition method}

Decomposition analysis can be divided into Structural Decomposition Analysis (SDA) and Index Decomposition Analysis (IDA). SDA is generally combined with the input-output table. However, China publishes the input-output table every five years, so the availability of relevant data is poor. IDA only needs sector-lever aggregate data, so it is more flexible to use. LMDI method is an IDA method proposed by Ang et al ${ }^{[4-}$ 5]. Because of advantages of no residual items and so on, it has been widely used in the fields of energy and environment. The study on application of LMDI method in industrial field is shown in Table 1. LMDI method is widely used in the field of water and carbon, but rarely used in the field of solid waste. Most scholars decomposes aggregate indicator based on factors in terms of intensity, structure change and output, and intensity is often defined as a technical factor.

Table 1 Literature on application of LMDI method in industrial field

\begin{tabular}{lcl}
\hline Authors & Aggregate indicator & \multicolumn{1}{c}{ Influencing factors } \\
\hline${\text { Chen et } \mathrm{al}^{[6]}}^{\text {Industrial }}$ & $\begin{array}{l}\text { Economic output, industrial } \\
\text { structure, industrial water } \\
\text { intensity }\end{array}$ \\
Shang et $\mathrm{al}^{[7]}$ & $\begin{array}{l}\text { Industrial } \\
\text { water use }\end{array}$ & $\begin{array}{l}\text { Industrial output value, } \\
\text { technology, industrial } \\
\text { structure }\end{array}$ \\
Quan et al ${ }^{[8]}$ & $\begin{array}{l}\text { Carbon emission coefficient, } \\
\text { energy intensity, energy } \\
\text { of logistics industry } \\
\text { structure, economic level and }\end{array}$ \\
\hline
\end{tabular}




\begin{tabular}{|c|c|c|}
\hline & & population size \\
\hline Fatima et al ${ }^{[9]}$ & $\begin{array}{c}\text { Industrial } \\
\mathrm{CO} 2 \text { emissions }\end{array}$ & $\begin{array}{l}\text { Energy structure effect, } \\
\text { income effect, energy } \\
\text { intensity effect, carbon } \\
\text { emission effect, and labor } \\
\text { effect }\end{array}$ \\
\hline Chen et $\mathrm{al}^{[10]}$ & $\begin{array}{l}\text { Industrial } \\
\text { solid waste }\end{array}$ & $\begin{array}{l}\text { Population, per capita GDP, } \\
\text { industrial structure, } \\
\text { investment intensity in } \\
\text { treatment of ISW, investment } \\
\text { efficiency of ISW recycle, } \\
\text { and ISWD intensity }\end{array}$ \\
\hline
\end{tabular}

\subsection{Decoupling analysis}

Decoupling refers to breaking the link between economic growth and resource consumption or environmental pollution. There are two main decoupling indicators frequently used. One is the decoupling indicator introduced by OECD ${ }^{[11]}$. The second decoupling indicator is the elastic indicator proposed by Tapio ${ }^{[12]}$. OECD indicator is sensitive to the choice of benchmark years, leading to the poor stability of the calculated results ${ }^{[13]}$. Tapio indicator is not limited by the length of time and can present decoupling states in more refined details ${ }^{[14]}$. Therefore, it is widely used. The study on the use of Tapio indicator is shown in Table 2. In the existing research literature, the decoupling analysis of industrial solid waste is rarely seen.

Table 2 Literature on application of Tapio indicator

\begin{tabular}{|c|c|c|}
\hline Authors & Countries/Cities & Pollutants \\
\hline Hu et $\mathrm{al}^{[15]}$ & 57 BRI countries & Carbon dioxide emissions \\
\hline $\mathrm{Xia}$ et $\mathrm{al}^{[16]}$ & Zhejiang, China & $\begin{array}{l}\text { Industrial air pollutant } \\
\text { emissions }\end{array}$ \\
\hline Wang et $\mathrm{a}^{[17]}$ & China & $\begin{array}{l}\mathrm{CO} 2 \text { emissions in the } \\
\text { iron and steel industry }\end{array}$ \\
\hline Qian et al ${ }^{[18]}$ & China & $\begin{array}{l}\text { Industrial sulfur dioxide } \\
\text { emissions }\end{array}$ \\
\hline Wang et $\mathrm{al}^{[19]}$ & China & $\begin{array}{l}\mathrm{CO} 2 \text { emissions of China's } \\
\text { metal industry }\end{array}$ \\
\hline
\end{tabular}

Decoupling analysis alone cannot evaluate the effects of environmental externalities and capture useful information ${ }^{[20]}$. This paper jointly uses LMDI method and decoupling analysis. Firstly, the driving factors of industrial solid waste production are decomposed into industrial pollution intensity effect, industrial structure effect, regional output effect and population size effect. On this basis, the decoupling relationship between industrial solid waste and industrial added value is investigated.

\section{Methods and data}

\subsection{LMDI decomposition model}

LMDI method is used to decompose industrial solid waste production:

$$
I S W=\frac{I S W}{I A V} \times \frac{I A V}{G} \times \frac{G}{P} \times P
$$

Where, $I S W$ refers to industrial solid waste production, $I A V$ refers to industrial added value, $G$ refers to GDP and $P$ refers to the population. Rewrite equation (1) as:

$$
I S W=I P I \times S \times R O \times P
$$

Where, $I P I=\frac{I S W}{I A V}$ refers to the industrial pollution intensity, which is mainly related to technical factors such as clean production. $S=\frac{I A V}{G}$ refers to the industrial structure. $R O=\frac{G}{P}$ refers to the regional output level.

The change of industrial solid waste production can be decomposed into four driving factors:

$$
\begin{gathered}
\Delta I S W=\Delta I S W_{I P I}+\Delta I S W_{S}+\Delta I S W_{R O}+\Delta I S W_{P} \\
\Delta I S W_{I P I}=\frac{I S W^{t}-I S W^{0}}{\ln I S W^{t}-\ln I S W^{0}} \ln \left(\frac{I P I^{t}}{I P I^{0}}\right) \\
\Delta I S W_{S}=\frac{I S W^{t}-I S W^{0}}{\ln I S W^{t}-\ln I S W^{0}} \ln \left(\frac{S^{t}}{S^{0}}\right) \\
\Delta I S W_{R O}=\frac{I S W^{t}-I S W^{0}}{\ln I S W^{t}-\ln I S W^{0}} \ln \left(\frac{R O^{t}}{R O^{0}}\right) \\
\Delta I S W_{P}=\frac{I S W^{t}-I S W^{0}}{\ln I S W^{t}-\ln I S W^{0}} \ln \left(\frac{P^{t}}{P^{0}}\right)
\end{gathered}
$$

Where, $\Delta I S W_{I P I}, \quad \Delta I S W_{S}, \quad \Delta I S W_{R O}$ and $\triangle I S W_{P}$ respectively represent the contribution of industrial pollution intensity effect, industrial structure effect, regional output effect and population size effect to the change of industrial solid waste production.

\subsection{Tapio indicator}

The Tapio indicator associated with industrial solid waste production and industrial added value is constructed, as shown in the formula (8):

$$
\lambda=\frac{I S W^{t}-I S W^{0}}{I S W^{0}} / \frac{I A V^{t}-I A V^{0}}{I A V^{0}}
$$

Where, $\lambda$ refers to the Tapio indicator, $I S W^{t}$ and $I A V^{t}$ respectively refer to industrial solid waste production and industrial added value in phase T. $I S W^{0}$ and $I A V^{0}$ respectively refer to industrial solid waste production and industrial added value in the base period

Decoupling states can be classified into three categories and eight sub-categories, as shown in Table 3.Strong decoupling state is most ideal and strong negative decoupling state is most unfavorable.

Table 3 Decoupling judgments of the Tapio indicator

\begin{tabular}{l|l|c|c|c}
\hline \multicolumn{2}{c|}{ State } & $\frac{I S W^{t}-I S W^{0}}{I S W^{0}}$ & $\frac{I A V^{t}-I A V^{0}}{I A V^{0}}$ & $\lambda$ \\
\hline Decoupling & $\begin{array}{l}\text { Strong } \\
\text { decoupling(SD) } \\
\text { Weak } \\
\text { decoupling(WD) } \\
\begin{array}{l}\text { Recessive } \\
\text { decoupling(RD) }\end{array}\end{array}$ & $<0$ & $>0$ & $(-\infty, 0)$ \\
\hline Coupling & $\begin{array}{l}\text { Recessive } \\
\text { coupling(RC) }\end{array}$ & $<0$ & $<0$ & $(0,0.8]$ \\
\hline
\end{tabular}




\begin{tabular}{|c|c|c|c|c|}
\hline & \begin{tabular}{|l} 
Expansive \\
coupling(EC)
\end{tabular} & $>0$ & $>0$ & $(0.8,1.2]$ \\
\hline \multirow[t]{3}{*}{$\begin{array}{l}\text { Negative } \\
\text { decoupling }\end{array}$} & $\begin{array}{l}\text { Expansive negative } \\
\text { decoupling(END) }\end{array}$ & $>0$ & $>0$ & $(1.2,+\infty)$ \\
\hline & $\begin{array}{l}\text { Strong negative } \\
\text { decoupling(SND) }\end{array}$ & $>0$ & $<0$ & $(-\infty, 0)$ \\
\hline & $\begin{array}{l}\text { Weak negative } \\
\text { decoupling(WND) }\end{array}$ & $<0$ & $<0$ & $(0,0.8)$ \\
\hline
\end{tabular}

\subsection{Data source and description}

This study focuses on the time span during 2005-2018. The data are from China Statistical Yearbook on Environment, statistical yearbooks of various provinces, and official website of China Bureau of Statistics. To eliminate the influence of price factor, the raw data of output has been measured at 2005 constant price.

According to Figure 1, from 2005 to 2018, the industrial solid waste production in the Yangtze River Economic Belt showed a fluctuating upward trend, rising from 462.09 million tons to 1171.08 million tons, with an average annual change rate of $7.42 \%$. The industrial added value showed a steady upward trend, rising from 3348.55 billion yuan in 2005 to 11562.44 billion yuan in 2018 , with an average annual change rate of $10.00 \%$.

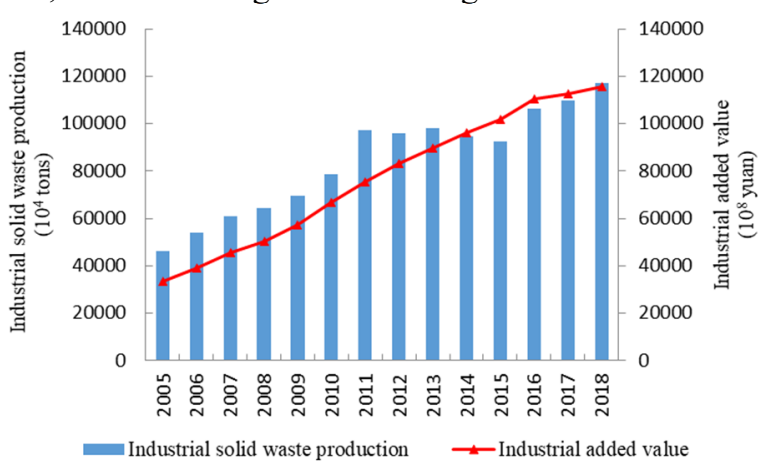

Fig.1. Trend of industrial solid waste production and industrial added value in the Yangtze River Economic Belt from 2005 to 2018

\section{Results}

\subsection{Driving effect decomposition of industrial solid waste production}

The cumulative effect value of each driving factor of industrial solid waste production in the Yangtze River Economic Belt from 2005 to 2018 was calculated, as shown in Table 4.

Table 4 Decomposition of changes in industrial solid waste production in the Yangtze River Economic Zone from 2005 to 2018 ( $10^{4}$ tons $)$

\begin{tabular}{cccccc}
\hline Region & $\Delta I S W_{I P I}$ & $\Delta I S W_{S}$ & $\Delta I S W_{R O}$ & $\Delta I S W_{P}$ & $\Delta I S W$ \\
\hline Shanghai & -1864.49 & -339.72 & 1565.64 & 466.95 & -171.62 \\
Jiangsu & -3721.65 & -589.22 & 11049.29 & 527.21 & 7265.63 \\
Zhejiang & -366.52 & -981.24 & 4010.51 & 543.24 & 3206.00 \\
Anhui & -2133.79 & 1445.13 & 11679.34 & 283.32 & 11274.00 \\
Jiangxi & -7759.20 & 92.05 & 12086.83 & 702.60 & 5122.29 \\
Hubei & -2945.34 & 1288.24 & 9248.02 & 245.07 & 7836.00 \\
Hunan & -3292.95 & -279.82 & 5933.63 & 399.71 & 2760.56 \\
Chongqing & -2321.04 & -182.55 & 3158.91 & 225.68 & 881.00 \\
\hline
\end{tabular}

\begin{tabular}{cccccc}
\hline Sichuan & -4206.97 & -371.67 & 14698.10 & 167.66 & 10287.13 \\
Yunnan & 1424.54 & -371.82 & 13196.53 & 856.75 & 15106.00 \\
Guizhou & -4808.61 & 545.64 & 11877.54 & -282.57 & 7332.00 \\
Economic & -23582.56 & -5066.01 & 94620.31 & 4927.25 & 70898.99 \\
Belt & & & & \\
\hline
\end{tabular}

According to Table 4, for industrial solid waste in the Yangtze River Economic Belt from 2005 to 2018, the industrial pollution intensity effect was -235.83 million tons, reaching $-33.26 \%$ of the total effect, which was the primary factor to reduce industrial solid waste production. The industrial structure effect was -50.66 million tons, reaching $-7.15 \%$ of the total effect, which was the secondary factor to reduce industrial solid waste production. The regional output effect was 946.20 million tons, reaching $133.46 \%$ of the total effect. The population size effect was 49.27 million tons, reaching $6.95 \%$ of the total effect. Comparing the absolute value of each effect, we can find that regional output effect $>$ industrial pollution intensity effect $>$ industrial structure effect $>$ population size effect. The absolute value of regional output effect was about 4.01 times of that of industrial pollution intensity effect.

Furthermore, from the provincial perspective, we can find that: (1) Except Yunnan, the industrial pollution intensity effect was negative in all provinces, indicating that the industrial solid waste production per unit of industrial added value was reduced in most regions. This was mainly due to the improvement of pollution control technology. Among the provinces, the industrial pollution intensity effect in Jiangxi was the most significant; (2)the industrial structure effect in Anhui, Jiangxi, Hubei and Guizhou was positive, which indicated that promoting industrialization would aggravate environmental pollution and increase solid waste. Among the provinces, the industrial structure effect in Anhui was the most significant, which indicated that Anhui greatly sacrificed the environment in the process of industrialization; (3) the regional output effect in all provinces was positive, indicating that economic growth intensified resource consumption and stimulated the increase of industrial solid waste; (4) except Guizhou, the population size effect in all provinces was positive. The increase of population brought about the increase in labor force and the expansion of consumption market, which would stimulate industrial production and lead to the increase in the industrial solid waste; (5) except Shanghai, the industrial solid waste production in all provinces showed an upward trend. Shanghai took the finance industry as the pillar industry, and actively developed the high-tech environmental industry, which alleviated the solid waste pollution. Among other provinces, Yunnan's production of industrial solid waste increased most significantly, reaching 151.06 million tons. The pillar industries of Yunnan included mining industry and electric power industry. Mining and the construction of water conservancy and hydropower projects could produce a large number of solid wastes, resulting in the aggravation of pollution. 


\subsection{Decoupling results}

China regularly promulgates the five-year plan, which is the outline of national economic operation and social development. Therefore, this paper divides the time interval into 2005-2010, 2010-2015 and 2015-2018.On this basis, we investigate the relationship between industrial solid waste production and industrial economy. The result is shown in Table 5.

Table 5 Decoupling states of industrial solid waste in the Yangtze River Economic Belt from 2005 to 2018

\begin{tabular}{ccccccc}
\hline & \multicolumn{2}{c}{$2005-2010$} & $2010-2015$ & $2015-2018$ \\
\cline { 2 - 7 } Region & $\lambda$ & state & \multicolumn{1}{c}{$\lambda$} & state & $\lambda$ & state \\
\hline Shanghai & 0.40 & WD & -1.49 & SD & -0.13 & SD \\
Jiangsu & 0.69 & WD & 0.34 & WD & 0.98 & EC \\
Zhejiang & 0.99 & EC & 0.32 & WD & 1.73 & END \\
Anhui & 0.78 & WD & 0.54 & WD & 3.84 & END \\
Jiangxi & 0.28 & WD & 0.22 & WD & 1.62 & END \\
Hubei & 0.61 & WD & 0.20 & WD & 2.68 & END \\
Hunan & 0.53 & WD & 0.32 & WD & 1.60 & END \\
Chongqing & 0.39 & WD & -0.03 & SD & -0.79 & SD \\
Sichuan & 0.50 & WD & 0.19 & WD & 13.67 & END \\
Yunnan & 1.11 & EC & 0.85 & EC & 1.87 & END \\
Guizhou & 0.92 & EC & -0.11 & SD & 4.13 & END \\
Economic Belt & 0.71 & WD & 0.33 & WD & 1.99 & END \\
\hline
\end{tabular}

In different periods, the decoupling states of industrial solid waste in the Yangtze River Economic Belt were weak decoupling, weak decoupling and expansive negative decoupling. The decoupling indicator showed a trend of first decreasing and then increasing, which reflected the repeatability and difficulty of solid waste pollution treatment.

In the period of $2005-2010$, (1) $72.73 \%$ of provinces were in weak decoupling state, and $27.27 \%$ of provinces were in expansive coupling state. The latter included Zhejiang, Yunnan and Guizhou; (2)for Zhejiang, there were many industrial enterprises whose extensive production modes generated a large number of solid wastes. For Yunnan and Guizhou, they took the opportunity of the "Development of the Western Region in China" strategy and "West-East Electricity Transmission" project, and increased their investment and construction in power projects from 2005 to 2010 . However, the production of hydropower and thermal power increased the industrial solid waste significantly.

In the period of $2010-2015$, (1) $27.27 \%$ of provinces were in strong decoupling state, $63.64 \%$ of provinces were in weak decoupling state, and $9.09 \%$ of provinces were in expansive coupling state; (2) Shanghai, Chongqing, Guizhou were in strong decoupling state. This showed that they had strengthened environmental control and improved clean transformation; (3) Yunnan was in expansive coupling state. In order to build a moderately prosperous society in step with the whole country in the future, during the 12th Five-Year Plan period, Yunnan took promoting economic development as the main goal. The average annual economic growth rate of Yunnan, reaching $11.1 \%$, was 3.3 percentage points higher than that of the whole country. However, due to the relatively extensive development mode and low-end industrial division of labor, solid waste increased significantly in the process of industrial production.

In the period of $2015-2018$, (1) $18.18 \%$ of provinces were in strong decoupling state, $72.73 \%$ of provinces were in expansive negative decoupling state, and 9.09\% of provinces were in expansive coupling state; (2) Shanghai and Chongqing were still in strong decoupling state, which reflected that they had made continuous progress in green transformation; (3)the decoupling state of Jiangsu changed from week decoupling to expansive coupling. Since there were many manufacturing enterprises in Jiangsu, the government had great pressure on the control of industrial solid waste pollution; (4)other provinces were in expansive negative decoupling state. From 2015 to 2018, industrial economic growth slowed down, and $\frac{I A V^{t}-I A V^{0}}{I A V^{0}}$ was quite small in these provinces, especially in Sichuan. In addition, the industrial solid pollution was deteriorating, which might be due to the bottleneck of pollution control technology. Thus, the $\lambda$ in these provinces was relatively big.

\section{Conclusions and policy}

In this paper, LMDI method is used to decompose industrial solid waste production in the Yangtze River Economic Belt from 2005 to 2018, and Tapio indicator is used to study the decoupling relationship between industrial solid waste and industrial economy. We find that:

(1) Industrial pollution intensity effect and industrial structure effect played a role in reducing industrial solid waste in the Yangtze River Economic Belt, and regional output effect and population size effect played a role in increasing the pollution. According to the absolute value of each effect, it can be found that regional output effect $>$ industrial pollution intensity effect $>$ industrial structure effect $>$ population size effect.

(2) In different periods, the decoupling states of industrial solid waste in the Yangtze River Economic Belt were weak decoupling, weak decoupling and expansive negative decoupling. The decoupling indicator showed a trend of first decreasing and then increasing. It was urgent to strengthen the control of industrial solid waste.

Based on the above results, this paper proposes the following suggestions:

(1) Enhance the research on solid waste reduction technology. To obtain technological breakthroughs, enterprises can strengthen cooperation with universities and scientific institutions.

(2) Promote the adjustment of industrial structure. In order to curb solid pollution, it is suggested to guide investment from pollution-intensive industries to environment-friendly and high-tech industries.

(3) Uphold the concept of high quality development and build an environment-friendly economic growth pattern. It is necessary to eliminate backward production capacity to restrain the increase of industrial solid waste

(4) The population layout should be rationally 
planned to prevent the industrial pollution surge caused by the excessive population concentration.

\section{References}

1. Zhou, B., Sun, C., Yi, H. (2017) Solid Waste Disposal in Chinese Cities: An Evaluation of Local Performance. Sustainability, 9(12):2234

2. Xu, B., Lin, B.Q. (2016) Assessing CO2 emissions in China's iron and steel industry: a dynamic vector autoregression model. Appl. Energ., 161:375-386

3. Chen, Y., Hu, N., Teng, J.G. (2017) A Study on the Resource Utilization Strategy for Industrial Solid Waste in China. Engineering Science, 19(4): 109114

4. Ang, B.W. (2004) Decomposition analysis for policymaking in energy: which is the preferred method? Energy Policy, 32: 1131-1139

5. Ang, B.W., Zhang, F.Q. (2000) A survey of index decomposition analysis in energy and environmental studies. Energy, 25: 1149-1176

6. Chen, L., Xu, L.Y., $\mathrm{Xu}, \mathrm{Q}$, et al. (2016) Optimization of urban industrial structure under the low-carbon goal and the water constraints: a case in Dalian, China. J. Clean. Prod., 114: 323-333.

7. Shang, Y.Z., Lu, S.B., Shang, L., et al. (2016) Decomposition methods for analyzing changes of industrial water use. J. Hydrol., 543: 808-817

8. Quan, C.G., Cheng, X.J., Yu, S.S., et al. (2020) Analysis on the influencing factors of carbon emission in China's logistics industry based on LMDI method. Sci. Total Environ., 734: 138473

9. Fatima, T., Xia, E., Cao, Z., et al. (2019) Decomposition analysis of energy-related $\mathrm{CO} 2$ emission in the industrial sector of China: Evidence from the LMDI approach. Environ Sci. Pollut. Res., 26: 21736-21749

10. Chen, X., Pang, J., Zhang, Z., et al. (2014) Sustainability Assessment of Solid Waste Management in China: A Decoupling and Decomposition Analysis. Sustainability, 6: 92689281

11. OECD, R. (2002) Indicators to measure decoupling of environmental pressure from economic growth. OECD, Paris.

12. Tapio, P. (2005) Towards a theory of decoupling: degrees of decoupling in the EU and the case of road traffic in Finland between 1970 and 2001. Transp. Policy, 12: 137-151

13. Zhao, X., Zhang, X., Shao, S. (2016) Decoupling $\mathrm{CO} 2$ emissions and industrial growth in China over 1993-2013: the role of investment. Energy Econ., 60: 275-292

14. Wu, Y., Zhu, Q.W., Zhu, B.Z. (2018) Decoupling analysis of world economic growth and $\mathrm{CO} 2$ emissions: A study comparing developed and developing countries. J. Clean. Prod., 190: 94-103.

15. Hu, M.J., Li, R.Z., You, W.H., et al. (2020) Spatiotemporal evolution of decoupling and driving forces of $\mathrm{CO} 2$ emissions on economic growth along the Belt and Road. J. Clean. Prod., 277:123272

16. Xia, H.H., Ding, L., Yang, S.W., et al. (2020) Socioeconomic factors of industrial air pollutants in Zhejiang Province, China: Decoupling and Decomposition analysis. Environ. Sci. Pollut. R., 27(22): 28247-28266.

17. Wang, X.L., Wei, Y.W., Shao, Q.L.(2020) Decomposing the decoupling of CO 2 emissions and economic growth in China's iron and steel industry. Resour. Conserv. Recy., 152: 104509

18. Qian, Y., Cao, H., Huang, S.M. (2020) Decoupling and decomposition analysis of industrial sulfur dioxide emissions from the industrial economy in 30 Chinese provinces. J. Environ. Manage., 260: 110142

19. Wang, M., Feng, C. (2019) Decoupling economic growth from carbon dioxide emissions in China's metal industrial sectors: A technological and efficiency perspective. Sci. Total Environ., 691: 1173-1181.

20. Diakoulaki, D., Mandaraka, M. (2007) Decomposition analysis for assessing the progress in decoupling industrial growth from $\mathrm{CO} 2$ emissions in the EU manufacturing sector. Energy Econ., 29: 636-664. 